\title{
TU/e emonownen

\section{Application of a permanent magnet biased E-Core reluctance actuator in a magnetically suspended ceiling actuator}

\section{Citation for published version (APA):}

Overboom, T. T., Jansen, J. W., \& Lomonova, E. (2010). Application of a permanent magnet biased E-Core reluctance actuator in a magnetically suspended ceiling actuator. IEEE Transactions on Magnetics, 46(6), 21282131. https://doi.org/10.1109/TMAG.2010.2045112

DOI:

10.1109/TMAG.2010.2045112

Document status and date:

Published: 01/01/2010

\section{Document Version:}

Publisher's PDF, also known as Version of Record (includes final page, issue and volume numbers)

\section{Please check the document version of this publication:}

- A submitted manuscript is the version of the article upon submission and before peer-review. There can be important differences between the submitted version and the official published version of record. People interested in the research are advised to contact the author for the final version of the publication, or visit the DOI to the publisher's website.

- The final author version and the galley proof are versions of the publication after peer review.

- The final published version features the final layout of the paper including the volume, issue and page numbers.

Link to publication

\section{General rights}

Copyright and moral rights for the publications made accessible in the public portal are retained by the authors and/or other copyright owners and it is a condition of accessing publications that users recognise and abide by the legal requirements associated with these rights.

- Users may download and print one copy of any publication from the public portal for the purpose of private study or research.

- You may not further distribute the material or use it for any profit-making activity or commercial gain

- You may freely distribute the URL identifying the publication in the public portal.

If the publication is distributed under the terms of Article 25fa of the Dutch Copyright Act, indicated by the "Taverne" license above, please follow below link for the End User Agreement:

www.tue.nl/taverne

Take down policy

If you believe that this document breaches copyright please contact us at:

openaccess@tue.nl

providing details and we will investigate your claim. 


\title{
Application of a Permanent Magnet Biased E-Core Reluctance Actuator in a Magnetically Suspended Ceiling Actuator
}

\author{
T. T. Overboom, J. W. Jansen, and E. A. Lomonova \\ Eindhoven University of Technology,Department of Electrical Engineering, Electromechanics \& Power Electronics (EPE) \\ Group, 5612 AZ Eindhoven, The Netherlands
}

In the paper a novel actuator is presented for a magnetically suspended ceiling actuator. The actuator consists of several stator segments which contain the coils and the magnets. The armature, therefore, has a totally passive design. Because of its salient structure, a translational force can be produced for motion of the armature. The magnets create a passive attraction force for failsafe operation, which can be controlled for magnetically suspending the armature. Decoupling of the attraction and translational force, however, is complex, because they are strongly coupled. Therefore, position and current dependent force models are created based on curve fitting of inductances. It is shown that using these models, decoupling of the attraction and translational force in the ceiling actuator is possible.

Index Terms-Magnetic levitation, reluctance machines.

\section{INTRODUCTION}

A permanent magnet biased E-core reluctance actuator (PMECRA), as shown in Fig. 1, is investigated for application in a magnetically suspended ceiling actuator. In the figure, part of the ceiling actuator is shown, which contains three stator segments. The structure of each stator segment is similar to a design of a reluctance actuator, which is used for valve actuation inside a combustion engine [1]. In the ceiling actuator the armature has a salient structure in order to create a translational force. Because the magnets and the coils are embedded inside the stator of the ceiling actuator, the armature has a simple and fully passive construction.

In the ceiling actuator, a passive upward attraction force is required to prevent the armature from falling down in case of a power failure. Therefore, unlike a magnetically suspended planar actuator [2], in the ceiling actuator iron has to be employed into the structure in order to create passive upward attraction force between the iron and the magnets. The main challenge, though, is to actively reduce this passive attraction force to stably suspend the armature and also to create a translation force to provide motion of the platform. Both forces, however, are strongly coupled.

In this paper, first the basic operating principles of the pm biased e-core actuator are explained. Next, position dependent models for both the attraction and translational force are derived, which also describe the force dependency on the current. Finally, based on these models, it is shown that the forces can be decoupled by appropriately commutating currents inside the three stator segments from Fig. 1.

\section{OPERATING PRINCIPLES}

The operating principle of the PMECRA can be explained by considering a single stator segment, as is shown in Fig. 2. In the absence of any current inside the coil, the magnet creates a passive attraction force, $F_{z}$, between the stator and the armature.

Manuscript received October 31, 2009; revised January 15, 2010; accepted February 21, 2010. Current version published May 19, 2010. Corresponding author: T. T. Overboom (e-mail: t.t.overboom@tue.nl).

Color versions of one or more of the figures in this paper are available online at http://ieeexplore.ieee.org.

Digital Object Identifier 10.1109/TMAG.2010.2045112

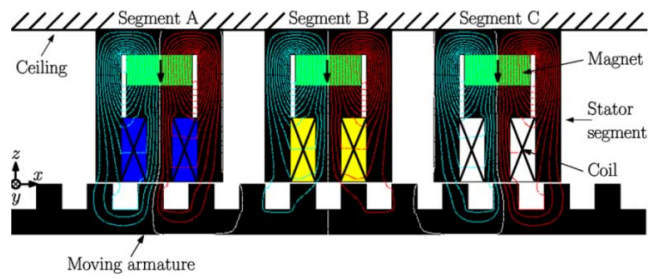

Fig. 1. Ceiling actuator containing three permanent magnet biased E-core actuators.

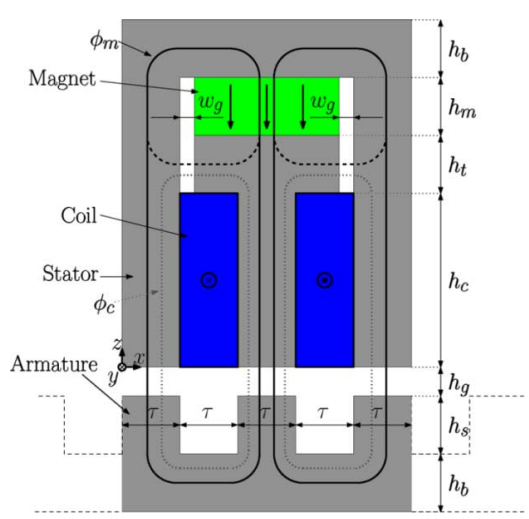

Fig. 2. Dimension and operating principles of a single permanent magnet biased E-core actuator.

By imposing a negative DC current through the coil, a coil flux, $\phi_{c}$, is created which opposes the magnet flux, $\phi_{m}$ and the attraction force is reduced, as shown in Fig. 3. The figure shows the attraction force as a function of the current density when the stator is aligned with the armature teeth. Similar to a reluctance actuator, the attraction force has a quadratic dependency on the current. However, in this case the graph is biased because of the magnet. The attraction force can be fully diminished for a certain current, though operating the current beyond this point is undesirable, because the same attraction force can be obtained with smaller amplitude of the current and, hence, with lower power losses.

Because of the salient structure of the armature, a translational component of the reluctance force is produced when the stator and armature teeth are unaligned. By appropriately commutating $\mathrm{AC}$ currents in each stator segment from Fig. 1, a net 


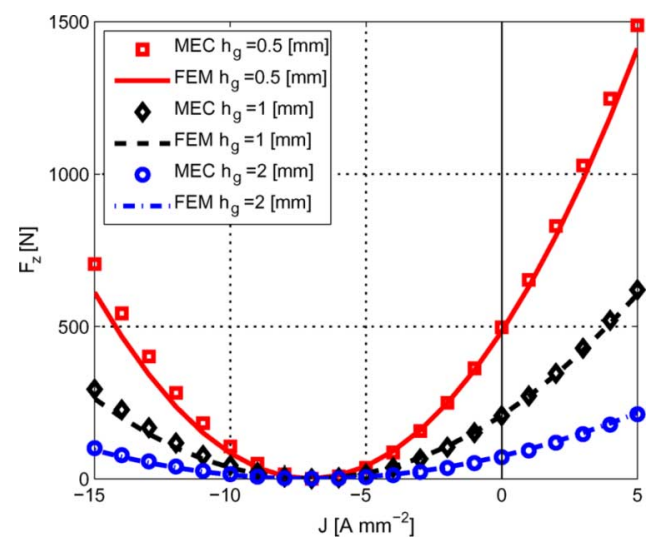

Fig. 3. Force-current characteristic of the pm biased E-core actuator for different airgap lengths.

TABLE I

DESIGN FOR THE PERMANENT MAGNET BiASED E-CORE RELUCTANCE ACTUATOR

\begin{tabular}{|c|c|c|}
\hline Description & Parameter & Value \\
\hline Slot pitch & $\tau$ & $10[\mathrm{~mm}]$ \\
\hline Width second airgap & $w_{g}$ & $4[\mathrm{~mm}]$ \\
\hline Slot height & $h_{s}$ & $10[\mathrm{~mm}]$ \\
\hline Coil height & $h_{c}$ & $25[\mathrm{~mm}]$ \\
\hline Tooth tip height & $h_{t}$ & $12.5[\mathrm{~mm}]$ \\
\hline Magnet height & $h_{m}$ & $12.5[\mathrm{~mm}]$ \\
\hline Core height & $h_{b}$ & $10[\mathrm{~mm}]$ \\
\hline Length of segment & $L$ & $50[\mathrm{~mm}]$ \\
\hline Remanent flux density & $B_{r e m}$ & $1.3[\mathrm{~T}]$ \\
\hline Coercivity & $H_{c}$ & $-0.985 \times 106\left[\mathrm{~A} \mathrm{~m}{ }^{-1}\right]$ \\
\hline Relative permeability magnet & $\mu_{r, m}$ & 1.05 \\
\hline Relative permeability iron & $\mu_{r, i}$ & $\infty$ \\
\hline
\end{tabular}

translational force, $F_{x}$, can be controlled. For the ceiling actuator the segments in Fig. 1 are shifted by $x=6 \tau+(2 / 3) \tau$ from each other. Inherently, in this actuator the translational force is much lower than the attraction force.

The translational and attraction force inside the actuator can be calculated by modeling the magnet as a coil with an equivalent current or magneto motive force (MMF), $i_{m}=-h_{m} H_{c}$. In the analysis of the forces no saturation inside the actuator is assumed. Therefore, $F_{z}$ and $F_{x}$ can be described through the change of magnetic energy in a linear and doubly excited system [3]

$$
\begin{aligned}
& F_{z}=\frac{1}{2} i_{c}^{2} \frac{d L_{c}}{d z}+i_{c} i_{m} \frac{d M}{d z}+\frac{1}{2} i_{m}^{2} \frac{d L_{m}}{d z} \\
& F_{x}=\frac{1}{2} i_{c}^{2} \frac{d L_{c}}{d x}+i_{c} i_{m} \frac{d M}{d x}+\frac{1}{2} i_{m}^{2} \frac{d L_{m}}{d x}
\end{aligned}
$$

where $L_{c}$ is the self inductance of the coil, $L_{m}$ is the self inductance of the coil equivalent of the magnet, $M$ is the mutual inductance between both coils and $i_{c}$ is the coil current. Both forces are calculated on the armature, where the relative displacement of the armature to the stator is $x$ in the translation direction and $z=-h_{g}$ in the normal direction.

In Table I, dimensions are given for a design of the structure which is shown in Fig. 2. Throughout the paper, this design will be used. The design achieves a passive elevation force of $F_{z 0}=$ $207 \mathrm{~N}$ (airgap length is $1 \mathrm{~mm}$ ), which can be reduced to zero when the DC current density is equal to $-7 \mathrm{~A} \mathrm{~mm}^{-2}$.

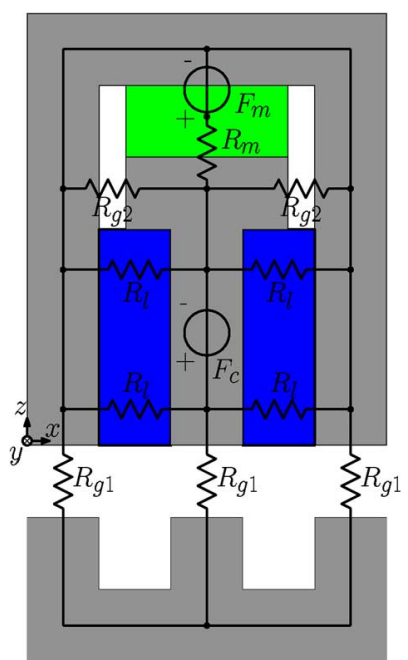

Fig. 4. Magnetic equivalent circuit of a permanent magnet biased E-core actuator.

\section{ReLuctance Model}

For the analysis of the PMECRA, a magnetic equivalent circuit (MEC) or reluctance model is created [4]. In Fig. 4 the reluctance model is shown when the stator and armature teeth are aligned. The reluctances are calculated according to [5]

$$
\begin{aligned}
R_{g 1}(z) & =\frac{1}{\mu_{0}\left(\frac{\tau L}{z}+0.52(L+\tau)+0.308 z\right)} \\
R_{g 2} & =\frac{1}{\mu_{0}\left(\frac{h_{t} L}{w_{g}}+1.04\left(L+h_{t}\right)+0.616 w_{g}\right)} \\
R_{m} & =\frac{h_{m}}{\mu_{r, m} \mu_{0} L\left(3 \tau-2 w_{g}\right)} \\
R_{l} & =\frac{2 \tau}{\mu_{0} h_{c} L}
\end{aligned}
$$

The inductances per turn are obtained from the reluctance model and from Fig. 3 it can be concluded that the attraction force calculated with this model shows good agreement with FEM prediction obtained from FLUX 2D. The reluctance model, however, becomes inaccurate when the stator and armature teeth are unaligned and calculating the translational force is not possible. Therefore, the model is only sufficient for the design of the actuator.

\section{CuRve FitTing Inductance}

To calculate the translational and attraction force, expressions for $L_{c}, L_{m}$ and $M$ as function of $x$ and $h_{g}$ have to be determined. The position dependency of the inductances per turn is analyzed in FEM-package FLUX 2D and shown in Fig. 5. For different positions of the armature in $x$, the inductances in Fig. 5(b) show a sinusoidal behavior with an offset. Therefore, each inductance as function of $x$ is approximated with the following function

$$
L(x, z)=\hat{L}_{0}(z)+\hat{L}_{1}(z) \cos \left(\frac{\pi}{\tau} x\right)+\hat{L}_{3}(z) \cos \left(\frac{3 \pi}{\tau} x\right)
$$

where $\hat{L}_{0}(z), \hat{L}_{1}(z)$ and $\hat{L}_{3}(z)$ are the $z$-dependent amplitudes of the different harmonics. Because the inductances are inversely proportional to the $z$-position of the armature, as 

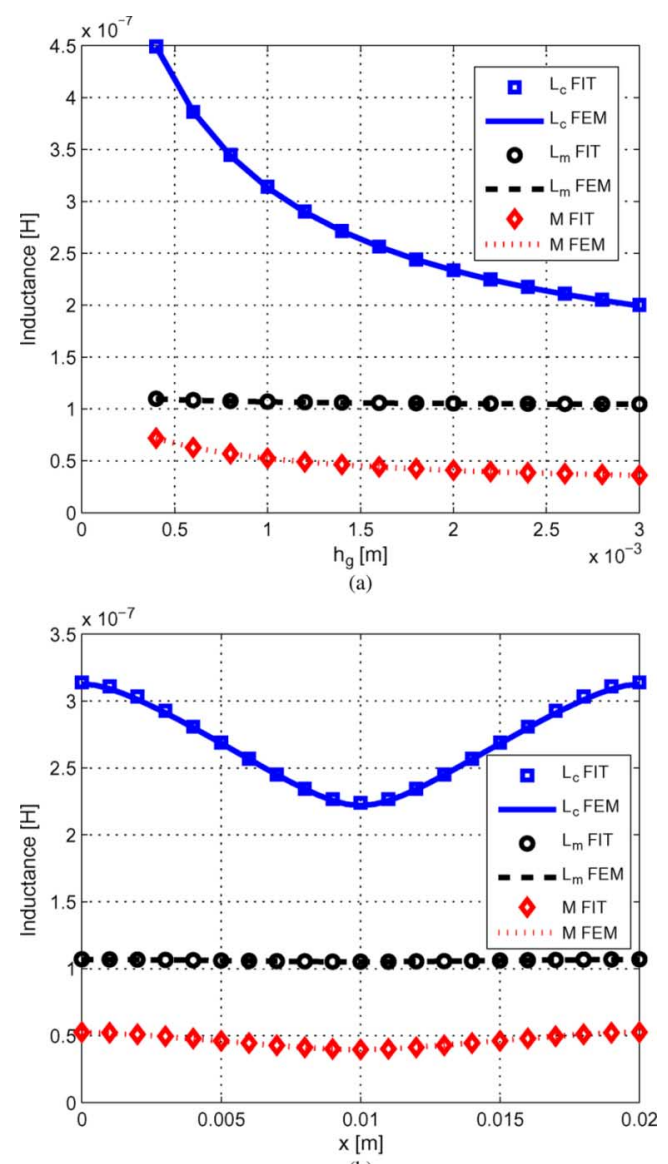

(b)

Fig. 5. Inductances per turn obtained from FEM and curve fitting as function of (a) the airgap length $(x=0)$ and (b) the translational position of the armature $\left(h_{g}=1 \mathrm{~mm}\right)$.

is shown in Fig. 5(a), the amplitude of each harmonic, $i$, is described by

$$
\hat{L}_{i}(z)=a_{i} z^{-3}+b_{i} z^{-2}+c_{i} z^{-1}+d_{i}
$$

where the coefficients $a_{i}, b_{i}, c_{i}$ and $d_{i}$ have to be obtained for each harmonic of the inductance. For translational positions of the armature which are equal to $x=0, \tau / 3$ and $\tau$, the following should hold:

$$
\begin{gathered}
L(x=0, z)=\hat{L}_{0}(z)+\hat{L}_{1}(z)+\hat{L}_{3}(z) \\
L(x=\tau / 3, z)=\hat{L}_{0}(z)+\frac{1}{2} \hat{L}_{1}(z)-\hat{L}_{3}(z) \\
L(x=\tau, z)=\hat{L}_{0}(z)-\hat{L}_{1}(z)-\hat{L}_{3}(z) .
\end{gathered}
$$

From this set of equations the amplitude of each harmonic can be expressed by the total inductance at the different positions in $x$. For the three positions of the armature in $x$, the total inductance is calculated with FEM when the $z$-position of the armature is ranged from $z=-h_{g}=-0.4$ to $-3 \mathrm{~mm}$. Through curve fitting on the results from FEM, the coefficients in (8) are obtained for the three inductances, $L_{c}, L_{m}$ and $M$, respectively. The fitted models described by (7) and (8) show good agreement with the FEM predictions, as shown in Fig. 5(a) and (b).

The models for the inductances are used to calculate the attraction and translational force according to (1) and (2). In Fig. 6, the attraction force as function of the airgap length is

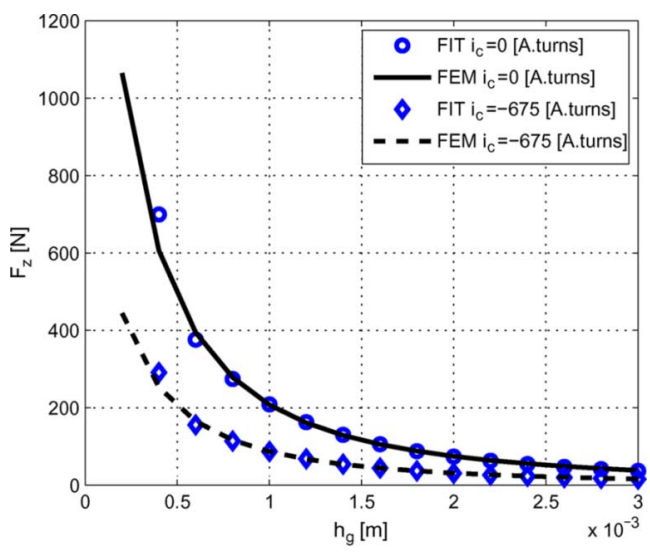

Fig. 6. Attraction force as function of the airgap length $(x=0)$.
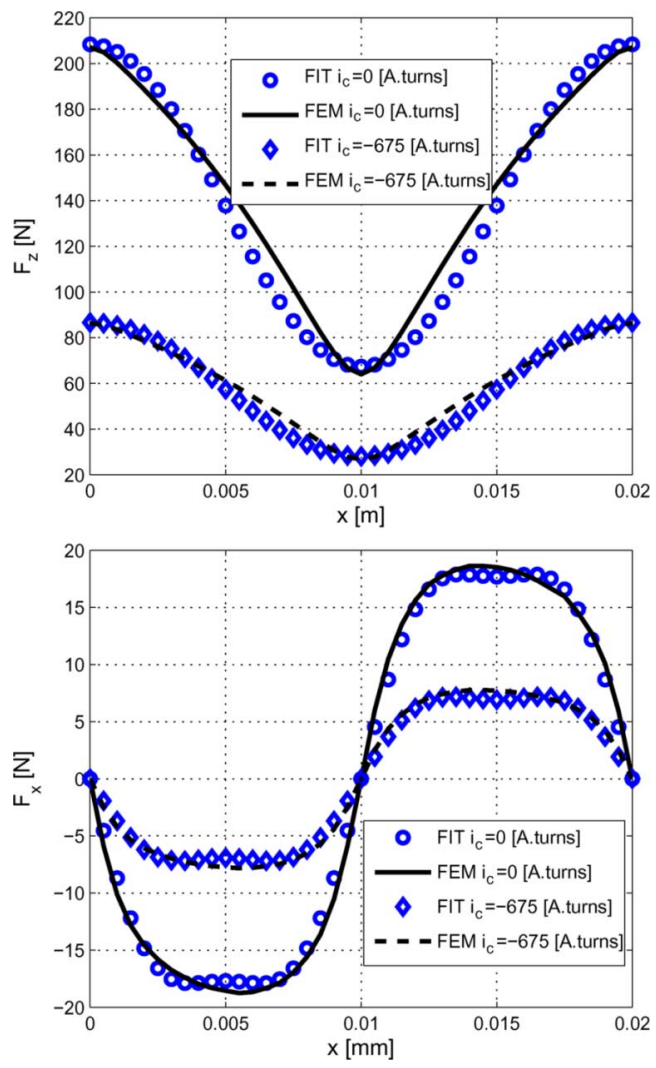

Fig. 7. $x$-dependency of the attraction force, $F_{z}$, and the translation force, $F_{x}$ $\left(h_{g}=1 \mathrm{~mm}\right)$.

shown for different values of the coil current when $x=0$. The force as function of $x$ when the airgap length is fixed to $1 \mathrm{~mm}$, is shown in Fig. 7. Both the attraction and translational forces calculated by the fitted model show good agreement with the result obtained from FEM.

\section{COMmutation}

With the obtained models, the force produced by each stator segment in Fig. 1 can be calculated. Because only part of the complete ceiling actuator is analyzed, torques created on the armature are ignored. As is discussed in Section II, an AC current is injected into the coils of each stator segments in order to create a net translational force. The attraction force, however, is mainly controlled by a DC current, which is the same in every stator 


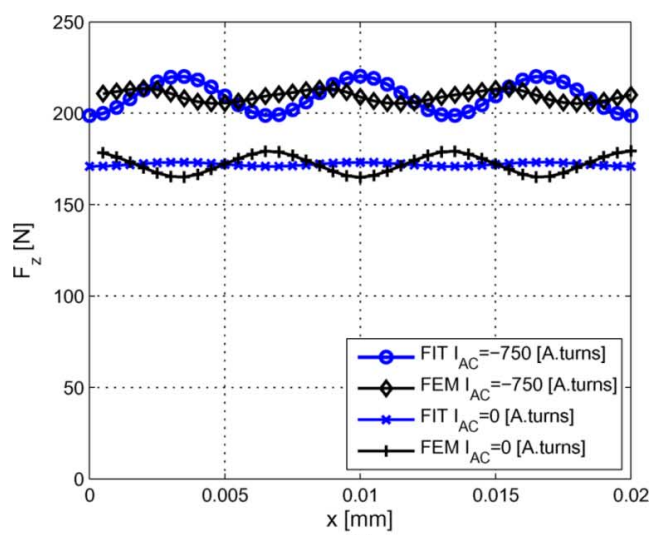

(a)

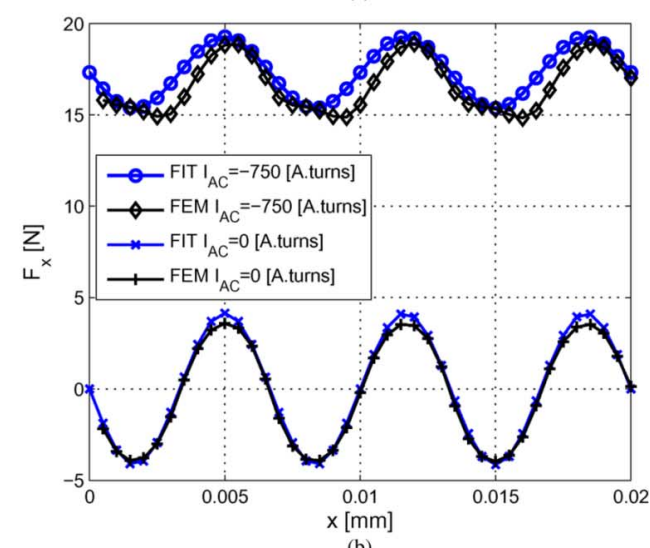

(b)

Fig. 8. Force profiles of ceiling actuator containing three PMECRAs with (a) the attraction force and (b) the translational force $\left(I_{D C}=-625\right.$ A.turns, $\left.h_{g}=1 \mathrm{~mm}\right)$.

segment. Therefore, the following currents for the different segments are proposed

$$
i_{c}=I_{D C}+I_{A C} \sin \left(\frac{\pi}{\tau}\left(x-k \frac{2 \tau}{3}\right)\right)
$$

where $k=0,1,-1$ for stator segment $A, B$ and $C$, respectively. In Fig. 8 the translational and attraction force calculated with the models obtained with curve fitting and FEM are shown when $I_{D C}=-625$ A.turns and $I_{A C}=0$ and $I_{A C}=-750$ A.turns. In the figure, it is clearly shown that the attraction force is increased due to the AC current, which indicates the coupling of the translational and attraction force. Both forces suffers from a large ripple, which is created by cogging force and higher harmonics which are not compensated by the current proposed in (8).

In order to decouple the translational and attraction force and to get a constant force profile, $I_{D C}$ and $I_{A C}$ need to be adjusted as the armature is moved along the stator. Using the description for the inductances in (7) and (8), the total translational and attraction force of the three stator segments together are solved for $I_{D C}$ and $I_{A C}$. Because the force has a non-linear dependency on

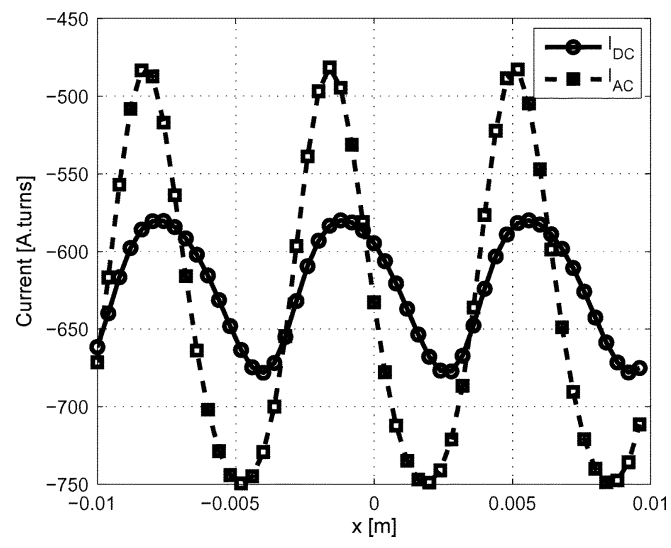

Fig. 9. Set points for $I_{D C}$ and $I_{A C}$ when $F_{x}=15 \mathrm{~N}$ and $F_{z}=200 \mathrm{~N}$ $\left(h_{g}=1 \mathrm{~mm}\right)$.

the current, a set of four solutions for $I_{D C}$ and $I_{A C}$ as function of the armature position and force set points, is obtained. From this set, the combination with lowest amplitude of the currents and, therefore, the lowest power losses, is chosen. For a given force set point with $F_{x}=15 \mathrm{~N}$ and $F_{z}=200 \mathrm{~N}$ and an airgap length of $1 \mathrm{~mm}$, the values for $I_{D C}$ and $I_{A C}$ as function of $x$ are shown in Fig. 9. The profiles for $I_{D C}$ and $I_{A C}$ have a dominant third harmonic, which is not included in (12). When the armature is moved along the stator, the total amplitude of both currents need to be adjusted by $8 \%$ and $21 \%$, compared to the average value, respectively.

This model-based commutation will be used inside a position feedback controller and is assumed to have sufficient decoupling to allow the use of separate single-input-single-output (SISO) controllers for the position of the mover in $x$ and $z$ [2]. In future work, measurements on a prototype will be carried out to experimentally verify this assumption.

\section{CONCLUSION}

In this paper, it is shown that a permanent magnet biased E-core reluctance actuator can be applied in a magnetically suspended ceiling actuator. For the topology, position and current dependent models for the attraction and translational force are obtained by curve fitting of the inductances. By appropriately commutating the currents, it is shown that the translational and attraction force can be decoupled and independently controlled.

\section{REFERENCES}

[1] J. Rens, R. E. Clark, and G. W. Jewell, "Static performance of a polarized permanent-magnet reluctance actuator for internal combustion engine valve actuation," IEEE Trans. Magn., vol. 42, no. 8, pp. 2063-2070, Aug. 2006.

[2] J. W. Jansen, C. M. M. van Lierop, E. A. Lomonova, and A. J. A. Vandenput, "Magnetically levitated planar actuator with moving magnets," IEEE Trans. Ind. Appl., vol. 44, no. 4, pp. 1108-1115, Jul. 2008.

[3] J. J. Cathey, Electric Machines. New York: McGraw-Hill, 2001.

[4] E. P. Furlani, Permanent Magnet and Electromechanical Devices: Materials, Analysis, and Applications. New York: Academic, 2001.

[5] H. C. Roters, Electromagnetic Devices. New York: Wiley, 1941. 